\title{
A Case Study on Performance Assessment Framework for Agile Processes
}

Keywords: SME, Gig economy, performance matrix, project management, Agile

This research investigates the implementation of Agile by an SME in the gig economy, focusing on developing an evaluation framework for performance assessment of the deployment of Agile method. We conceptualise and proposed a performance framework with both tangible and intangible indicators. Then, we test the applicability of the proposed framework through an in-depth case study. The findings suggest that the implementation of the planned Agile tools and processes have an impact on the firm performance as shown in the set of indicators. With Agile implementation, the firm performance was enhanced with an increase in the number of projects won and the increase in turnover, which are the tangible indicators. The intangible indicators, engagement and knowledge management, were also enhanced. But there are some concerns which firm should address.

\subsection{Introduction}

Businesses in gig-economy, also referred as collaborative-, sharing-economy, are increasingly occupying an important position, with serious economic and societal implications, in the modern digital society in recent years (Sundararajan 2014; Forman et al. 2008). The phenomenon of "Uberisation" has become very common and practiced in many industries, not only by big companies but also increasingly noticeable in SMEs. SMEs, becoming more entrepreneurial (Burtch et al., 2018), negotiate and engage in the gig economy in various ways, including when they are increasingly depending on the supply of knowledge and skills from many freelancers and self-employment workforces. it is to be noted that in many industries and settings, the mobility of labour might not be physical as it could be powered through the internet. This new trend in gig workforce enables SMEs to access to the required skills and knowledge from a global pool of talents, giving rise to the opportunities for disrupting long standing industries and displacing the incumbents (Morse, 2015; Zervas et al., 2015). While these businesses provide workers with an unprecedented degree of flexibility (Hall and Krueger 2018), they encounter many challenges, for instance, how to maintain performance, retain knowledge, and manage team. This research investigates the challenges related to maintaining performance where SMEs were under the nature of resource uncertainty while operate in the gig economy.

As SMEs, engaging in the gig economy, having a high number of freelances, they are thereby under the new norm of resource uncertainty. Those SMEs feel the need to alter their project management processes from the traditional method to an Agile approach. The Agile Manifesto (http://agilemanifesto.org/) calls for welcoming change through continuously develop-test-refine iterations in project development in order to increase the chances of success. This is in contrast to the traditional project management method of heavily upfront specification, i.e. the "waterfall" methodology (Jonasson, 2008), that often failed to deliver projects at great costs (Hardy-Vallee, 2012; Serrador and Pinto, 2015). By definition, Agile would seem at odds with estimating resources upfront which most businesses call for. For a more comprehensive review of the Agile method, its benefits and limitations see Dyba and Dingsoyr (2008). 
Can an enterprise really be Agile and have a high performance in the Gig economy? Dyba and Dingsoyr (2008) and other researchers (Boehm, 2002; Boehm and Turner, 2003; Cockburn, 2000) offer evidence suggesting that agile methods are not necessarily fit well with large projects, therefore suggesting that a carefully consideration of fit between project and method is warranted. The practitioners shall properly compare the projects' characteristics with the relevant agile methods' required characteristics. In contrast, Serrador and Pinto (2015), after analysed opinions of 859, mostly project managers, conclude that Agile methods do have a positive impact on both dimension of project success, i.e. project efficiency and stakeholder satisfaction. Following this line of discussion, this research investigates the implementation of Agile by SMEs in the gig economy through development of a performance measurement framework for this purpose.

Nonetheless, there is limited knowledge about their challenges and the effects on performance of Agile approach within the gig economy. This study aims to evaluate the deployment of Agile by investigating the performance in four respects pertaining to a digital enterprise, i.e. implementation success, knowledge management, worker engagement and brand citizenship. This research setting is primarily on SME deployment of Agile method within the gig economy. Through an in-depth case study, we develop a performance framework with tangible and intangible indicators for Agile application in SME.

\subsection{Agile, Gig and Knowledge Based Organisations}

The research is a single in-depth case study of a start-up enterprise. We selected a case of a small digital enterprise, $S H L$, who epitomises a gig economy corporation by providing a platform for a flexible workforce of self-employed and freelancers. It has attempted to reduce the uncertainty of their resource estimation through implementing a set of Agile tools and processes.

\section{The Agile Approach}

Evolved from the software community Agile, a manifesto invites change through continuous 'develop-test-refine' iterations in project development in order to increase the chances of success (Fowler and Highsmith, 2001). It addresses the challenges in the unpredicted real-world with great flexibility by relying on the people and their creativity, rather than a set of rigid fixed processes (Cockburn and Highsmith, 2001; Abrahamsson et al., 2002). For detailed description of the state of arts and practices of various Agile methods are available in Erickson et al. (2005) and Dingsoyr et al. (2012). This method has become a popular across-sector product development methodology, and particularly brought about a remarkable transformation and unprecedented changes in the software development field (Dingsoyr et al., 2012). It comes with tangible quantitative measures of success, such as increase in project success and projects won. Nevertheless, criticisms include the challenge of upfront uncertainty and the suitability to use in a distributed work teams (DeWitt, 2015).

Whilst it could well be argued that Agile simply frame-worked historic test and develop practices, for an SME, upfront uncertainty has caused issues such as eroding margins. The distributed work teams have also certainly caused issues such as output not meeting expectations. 


\section{Implementation of Agile in SHL}

In 2015/2016 SHL looked to adopt more Agile methodologies. SHL has particularly attempted to address the apparent dilemmas, over the last few years, by introducing Agile processes and complementary strategies namely:

- Breaking down projects into parts where estimation is gated by technical developer's approval

- Developing on boarding developer quality control through trial projects

- Developing coding development guidelines

- Introducing Agile Project Management tools such as bespoke Trello boards

- Encouraging inclusion and knowledge sharing through face to face contact and dedicated communication channels and online collaboration

- Rotating developer pairing

However, SHL has come to aware of the dilemmas that many enterprises faced; purely applying agile methodology inherently resulted in a lot of resource estimation uncertainties, particularly at the start of the project as depicted in the cone of uncertainty (McConnell, 1997).

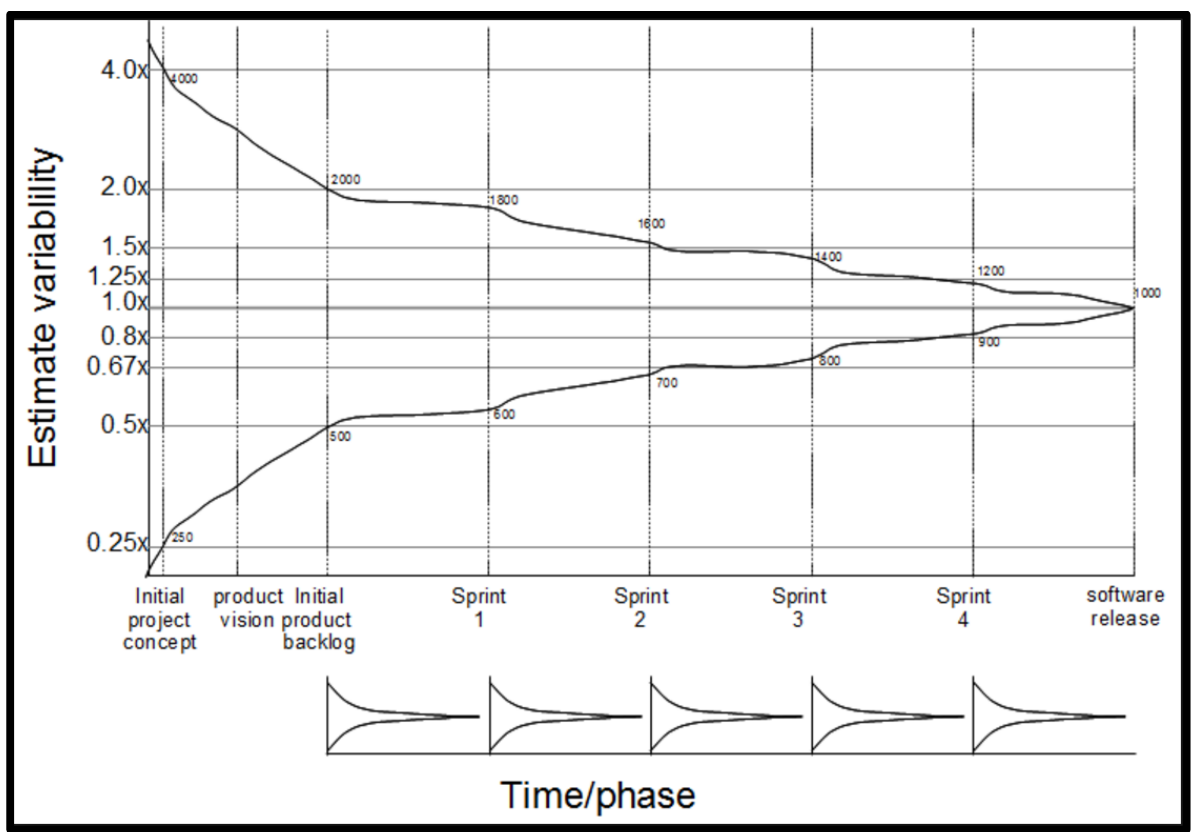

Figure 1: Cone of Uncertainty (McConnell, 1997)

Figure 1 depicts how it's not until you start to enter in later bursts of developments, called 'Sprints', does the uncertainty of the project decrease. As Tengeler (2014) summed up particularly for large projects, 'If your company has done a lot of similar projects you might be able to estimate the relative size of a project to other projects you have finished and make estimations that way. If the project is totally new and you are asked to estimate it, you are screwed! There is no way to accurately estimate a project at the beginning'.

\section{Engagement in the gig economy}

Whilst technology has facilitated the rise of sharing, collaborative and flexible working 
in the gig-economy, at the same time, emotional-derived intangible values (see Figure 2) such as employee engagement, in contrast to rational-derived values have become key metrics of employment satisfaction (Shook and Knickerehm, 2017). Similarly, McPherson (2015) reports, in order of ranking, the following key relevant metrics: personal development opportunities, confidence in leaders, effective use of resources, honest and open communications and leaders demonstrating people are important to a company's success.

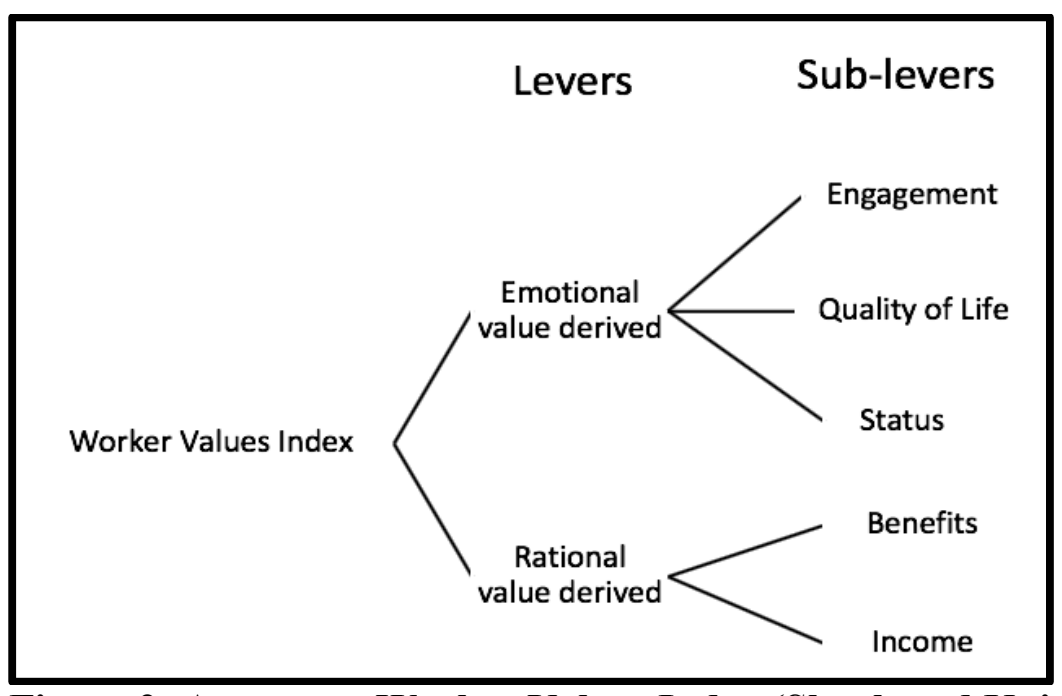

Figure 2: Accenture Worker Values Index (Shook and Knickerehm, 2017)

For SHL, the SME certainly could argue they have managed to keep a pool of quality gig workers at prices they could afford by focusing more on the emotional derived values and metrics. For examples, all software developers are actively encouraged to contribute ideas to the coding guidelines, and excellent workers are promoted on the company website.

\section{Issues of knowledge-based and brand citizenship}

Sveiby $(1997,2001)$ classically called for strategies, to manage intangible values in creative companies, in the form of structures to allow individual, internal and external knowledge sharing. Some contemporary scholars align to this but call for an intervention to ensure this happens (Mahesh and Suresh, 2009). Sveiby (2001) further argued for matching employees to clients to solve issues to maintain a corporation brand/image. Later scholars also appear to support this proposition, but contest that, in the digital age, aspects like brand citizenship, a measure of employee's intentional voluntary behaviour changes that strengthen the brand, is required to maintain a competitive advantage (Burmann et al., 2009).

Whilst, SHL use cloud tools such as Slack and Google drive to facilitate knowledge sharing. These kinds of practice would now seem very common amongst SMEs. It would also contribute to a better brand citizenship, by ensuring the enterprise practices the aforementioned emotion derived values making it a good place to work as well as developing certainly appears to workers. Examples of those practices are flexible working and opportunities given to work on a variety of projects. Although it is reasonably to predict that under the pressure to deliver projects, these values can often fall from being prioritised. 
Bringing the above analysis together this paper argues that: it is timely to assess the success of Agile implementations, in a gig economy, by using quantitative and qualitative measures of tangible and intangible aspects (i.e. implementation, engagement and knowledge management).

\subsection{Data collection and analysis method}

Data collection was conducted by a Practitioner-Researcher who was the company programme director. In addition to insider knowledge, we conducted one-to-one interview with another eight participants. The interviewees were selected using a specific criteria as suggested by Grummit (1980), such as in this case, interviewees were selected because they are considered to be the most active participants with the enterprise over 1996 -97, in the sense that they were the most engaged in projects of SHL. The interviews were carried out over several weeks with each interview taking around 45 minutes to complete. The roles of the participants varied from developer, associate, team leader to partner/client. These diverse selections of roles are meant to gain a wider range of insights and comparison of multiple perspectives.

\section{Interview Participants}

The anonymised interviewees were the leader and founder of the enterprise who is actively involved in the design and implementation and ongoing refinement of all the tools and processes. A partner-client who would be delivering a digital product to an end client and would engage with SHL to deliver/outsource part of the product, such as web development. In addition, two associates, who were on internships, based locally and involved in various projects in various ways including developing communication strategies, managing social media channels to promote both the clients and the enterprise. Another four interviewees were software developers, the real 'Giggers' who are/have all been engaged in working on specific SHL projects.

Each participant was asked around eight closed questions from an Assessment Framework constructed from the literature derived sub-themes of Implementation, engagement and knowledge management. After each question, the participants were then asked two open questions to gain more qualitative feedback, namely: What actions at the firm, if any, have made an impact in this area? How could the firm further make an impact in this area?

A Hybrid Assessment Framework was adopted out through thematic data analysis by the following procedure: summarising points raised, coding and categorising themes as suggested by Braun and Clarke (2006). The findings were then processed and presented with a series of graphs and tables and finally a structured narrative was developed to ensure the qualitative essence of the research findings were maintained.

\section{Performance Assessment Framework}

As well as evaluating the success of the Agile implementation, this case study provides an excellent opportunity to evaluate a proposed performance assessment framework. It was derived from the literature, and comprising of three key elements, i.e. Implementation, Engagement and Knowledge Management, and their sub-elements as summarised in Figure 3. 


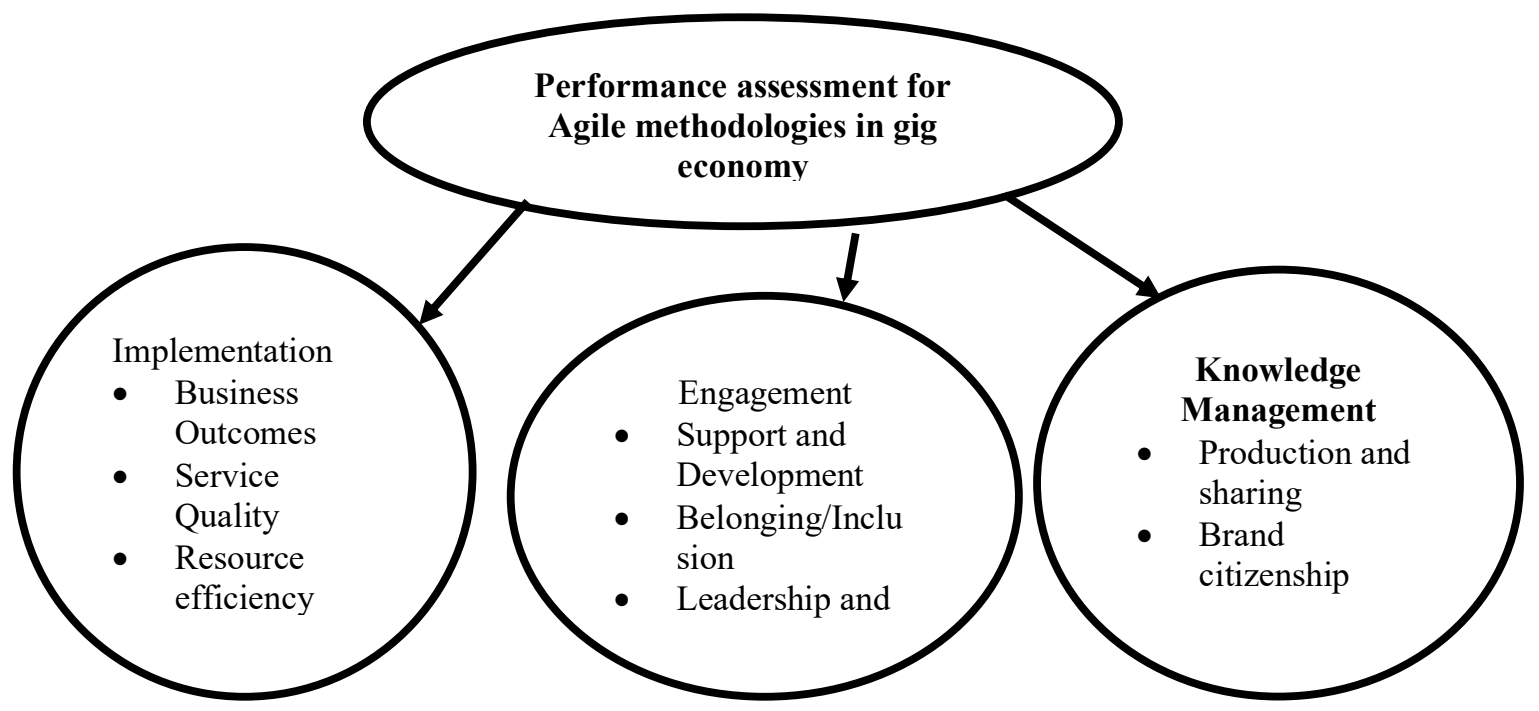

Figure 3: Performance Assessment Framework

Implementation is comprised of Business Outcomes metrics that measure how well the end product satisfies customer needs, leading to an increase in business value (Radigan, 2016). Agile Service Quality looks at the measurement if the process has actually reduced uncertainty through metrics such as less post-release issues (customer satisfaction), more accurate time scales (Dimachkie, 2016), and responsiveness to issues/requests. Resource efficiency measures at how efficiently internal resources are being utilized and matching personnel to clients' needs in terms of ability and cost (Sveiby, 2001), plus workflow structure (Olszewska et al., 2016).

Engagement can be further broken down into personal support and development opportunities (McPherson, 2015), sense of belonging/inclusion, demonstrated leadership and open/honest communications/trust (Storey et al., 2016; Shook and Knickerehm, 2017).

Finally, Knowledge Management comprises of knowledge production sharing; individual, internal or external (Sveiby, 2001) as well as brand citizenship through internal brand commitment, brand citizenship behaviour and brand - customer relationship (Burmann et al., 2009; Buil et al., 2014).

\subsection{Findings}

\section{Analysis of the answers for specific question}

The first two questions regarding business outcomes would be restricted to the business owners who answered that they are fully agree to both the turnover being improved and more projects being won after the implementation of agile approach. The rest of the interviewees were asked specific questions across the derived taxonomy (See Figure 3) of Implementation, Engagement and Knowledge Management, (As coded as group D, $\mathrm{E}$ and $\mathrm{F}$ questions respectively). Their responses were tabulated in Figure $\mathbf{4}$ as below: 


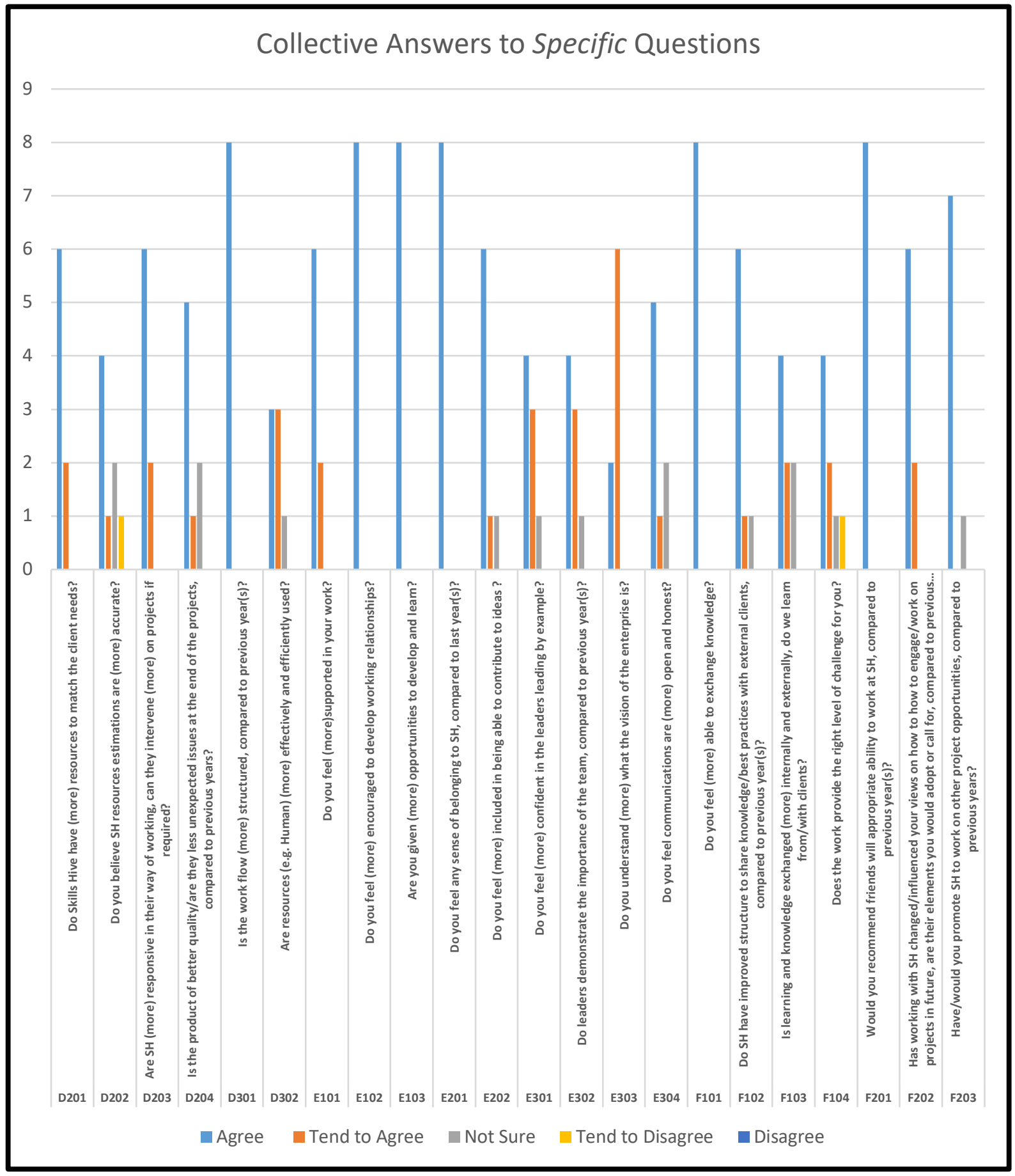

Figure 4: Responses on the questions of Implementation, Engagement and Knowledge Management.

\section{Breakdown of answers for open questions}

We asked two open questions as follows:

- What actions at SHL, if any, have made a (CURRENT) impact in this area?

- How could SHL FURTHER make an impact in this area?

After coding all the answers provided, the themes arose through the open questions of as shown in Figure 5 as below: 


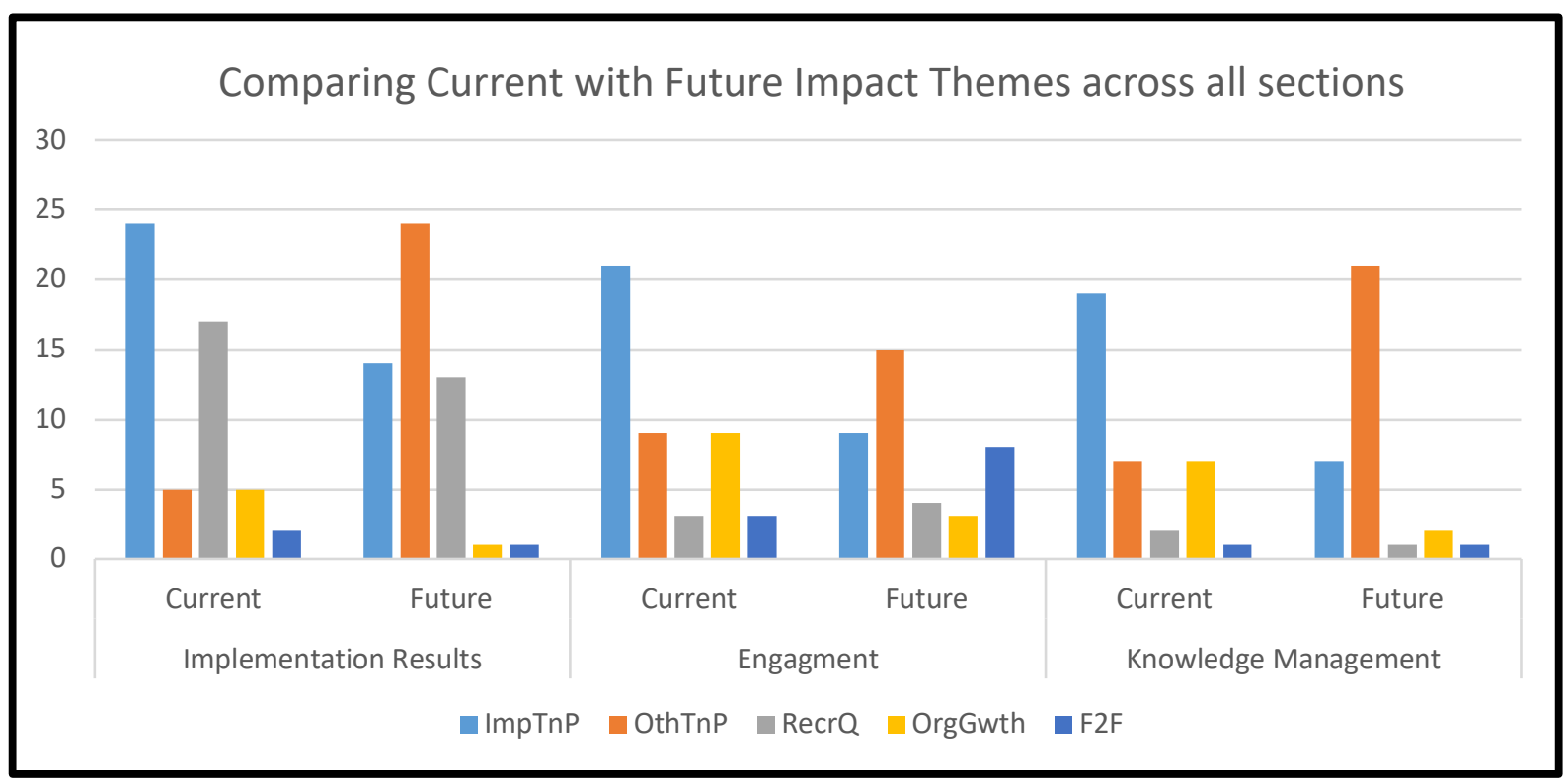

Figure 5: Current and Future Impact

Breaking down further into the three measurement criteria sections of Implementation, Engagement and Knowledge Management for the open questions, a fairly even spread is seen with implementation of listed Tools and Processes (ImpTnP) again dominating for current impact and Other Tool or Processes (OthTnP) became more prominent for future impact. Recruitment of Quality workers (RecrQ) is seen to be a more significant theme for the Implementation results. Organic development with worker and project (company) growth (OrgGwth) appeared to have most impact in the current engagement aspect. Whilst the Face to Face contact / reviews (F2F) occurred most for Future engagement impact.

\section{Structured Narrative - putting it all back together}

Following the Hybrid Analysis Framework, a structured narrative is now constructed from the data to provide a (defragmented) flow of participant's input in an attempt to ensure the qualitative essence of the research findings are maintained. The narrative is structured on the measurement performance criteria of Implementation Results, Engagement and Knowledge Management and sub-categories. Summarised 'quote' / briefer statement points as detailed above are inserted to add context and nuance to the narrative (Bryman and Bell, 2015).

\section{Implementation Results}

The leader fully Agreed that projects and turnover had increased and specifically referring to the implementation of Tools and Processes as 'Applying Agile and lean processes to expand capacity and efficiency plus freeze up time to invest in business development'. In an attempt to provide further triangulation of this result, due to the lack of other participants, with respect to these two initial questions, the leader was asked to examine his accounts and concluded that both turnover and the number of projects won had increased by $300 \%$.

Moving to service quality all participants tended to agree or agreed that the enterprise had more resources to match the client needs, although a major emergent theme was the Recruitment of Quality workers, one developer specifically mentioned the 
implementation of listed Tools and Processes along with the partner-client who also cited the increased Face to Face contact or reviews for technical liaison.

Considering if the enterprise's resource estimations are more accurate, a prime tangible goal of the implementation of the listed Tools and Processes, the participant's rating was more spread, although the partner-client fully agreed and attributed this to 'Fitting the team to the appropriate projects', the rest of the participants mentioned implementation of the listed Tools and Processes, except one developer, who tended not to agree and requested for further processes to get more developer input going forward.

For both being responsive and improved product quality the majority fully agreed on its improvement and cited implementation of the listed Tools and Processes across these open questions along with Recruitment of Quality workers or Organic development with worker and project (company) growth, although for responsiveness and quality the partner-client suggested further 'Being able to take the design as a creative guide and use technical ability to improve user experience' and 'Improve development time'. Which he/she also suggested helped with the next question of more structured workflow, whilst everyone else also unanimously agreed on the improvement and attributed this to the implementation of the listed Tools and Processes and generally called for more implementation/other Tools and Processes going forward, for example 'More guidelines around set-up of project' from a developer.

In terms of workers being used more effectively and efficiently most agreed or tended to agree and attributed this to Recruitment of Quality workers as the leader stated, 'Mixture of processes and network, bringing more people in with the right skills.'

\section{Engagement}

For being more supported the majority of the developers mentioned the implementation of the listed Tools and, whilst one associate and the leader mentioned Face to Face contact / reviews, although one Associate requested 'Less one to ones, more time for action' going forward'!

All unanimously agreed that they had been encouraged to develop working relationships with both the implementation of the new tools and organic development with worker and project (company) growth themes emerging about the same, 'working with other developers etc' summarised one developer. Going forward network events and social gatherings was mentioned by the Associates and a developer.

Whilst the vast majority agreed that the opportunities to develop and learn had increased no dominate theme seem to emerge although a couple of developers mentioned Organic development with worker and project (company) growth the leader detailed his intention to encourage event attendance and coaching plans. One developer suggested' A blog section, to blog outside on learning themes'.

For an increased sense of belonging all participants unanimously agreed, but again no dominate theme was found, although Organic development with worker and project (company) growth emerged twice and going forward three themes around other tools emerged such as 'Continue to communicate the aims of the business', from a developer. 
Most agreed with feeling more being able to contribute to ideas although no dominate theme emerged such as with the answers from one developer' Taking on-board your contributions'. However, going forward for the majority called for more Implementation of Planned Agile Tools and Processes tools.

For leaders leading by example all, but one, agreed or tended to agree, apart from one associate who was not sure. The Implementation of Planned Agile Tools and Processes emerged twice for current impact, but Face to Face contact/reviews was mentioned for future impact including a developer who requested 'for more help and advice through face to face'.

A similar spread of answers to the specific rating of leaders demonstrating importance of the team although the impact of the Implementation of Planned Agile Tools and Processes emerged much more here with one developer citing 'Responding to messages in slack'.

All participants agreed or tended to agree they understood the vision of the enterprise more although not prominent Implementation of Planned Agile Tools and Processes themes emerged, a couple also mentioned the Organic development with worker and project (company) growth plus Other Tools and processes going forward.

A majority agreed in feeling the communications were more open and honest with the Implementation of Planned Agile Tools and Processes along with Other Tools and processes emerging four times each on current impact summed up by developer $\mathrm{C}$ as 'Skype/slack comms etc'.

\section{Knowledge Management}

All participants fully agreed on being more able to exchange knowledge with themes of Recruitment of Quality workers and Organic development with worker and project (company) growth equally emergent three times, with Implementation of Planned Agile Tools and Processes and Other Tools and processes emerging three time for future such as developer A requesting 'Improve guidelines, share best practice'.

A majority believed the structure had improved to share knowledge/best practice with external clients and the Implementation of Planned Agile Tools and Processes theme emerged 6 times

Similarly results occurred for learning from/with clients, although Other Tools and processes emerged more such as the leader proposing 'post project introduction reviews (PIRs)'.

Whilst the majority agreed or tended to agree the right level of challenge was provided no dominate theme appeared to emerge here.

Finally, moving to Brand Citizenship, all unanimously agreed they would recommend friends to work at the enterprise more, although the only common theme was Organic development with worker and project (company) growth (OrgGwth) others did mention the work environment such as developer A providing a 'Nice to work with, culture, flexible'. Going forward several suggested other tools and processes to enhance this further with 'Clear and defined job descriptions' supplied by one associate. 
In terms of having influenced views from working at SHL the answers again were all positive, but this time the Implementation of Planned Agile Tools and Processes did dominate the theme 'Trello and slack etc' developer D.

The vast majority also agreed they would promote the enterprise more on project opportunities with Implementation of Planned Agile Tools and Processes, Recruitment of Quality workers and Organic development with worker and project (company) growth emerging twice each. The leader summing this up as 'Because the growing confidence of the core model is applicable across other areas, backed up by feedback'. Other tools such as social media were suggested to make a future impact going forward.

\subsection{Discussion and Conclusions}

This case study looked to evaluate the assessment framework that was developed and extracted from the literature review that proposed: To assess the success of methodology implementations in a gig economy, quantitative and qualitative measures of tangible and intangible aspects of the Implementation, Engagement and Knowledge Management incorporating image measures must be evaluated alongside each other

The case study was limited by the small size of the enterprise and so the focus was on a primarily qualitative study in the form of semi-structured interviews with input from all key stakeholders. As it's a small enterprise it's accepted the stability could be affected by the both the small sample size and the current status of the projects to which they are engaged, internal reliability needs consideration when comparing results, plus whilst, in terms of inter-rater reliability, there is only one researcher collecting and translating the data, the subjective nature of this process is open to scrutiny.

Nevertheless, the findings appear to demonstrate the Implementation of Planned Agile Tools and Processes having an impact in both tangible and intangible metrics, in agreement with the findings of other researchers, such as Serrador and Pinto (2015). The themes of impact of the new Agile tool and process was seen in both engagement and knowledge management measurement criteria. It would seem indeed that these more intangible measures are certainly important factors in at least partially assessing the implementation success. The theoretical assessment framework does seem to prove to be valid within this case study.

However, as well as the limitation of the small sample size it is noted that the Implementation of Planned Agile Tools and Processes were not alone and completely dominate in their impact, other themes particularly Organic development with worker and project (company) growth and Quality Recruitment of Quality workers came to fore during the interviews. The latter element appears to align with Sveiby's (1997) classic work on matching workers with client's needs being essential for a corporate image. The Implementation of Planned Agile Tools and Processes further emerged here as a factor in terms of the contemporary brand citizenship measures (Buil et al., 2014; Burmann et al., 2009) giving apparent reassurance to the call that every worker needs to live the brand to provide a competitive advantage in the in the digital age.

As well as providing an evaluation of the measures in the case study, this paper would also appear to provide a template for gig economy enterprises to measure both tangible and intangible key performance indicators. Whilst this would be most apparent for the enterprise in the case study, SHL, it could also be applicable for other least other gig 
economy enterprises that undisputable continue to grow. This research will contribute to the practice of SMEs, particularly those in the gig-economy, in the establishment of a better business performance metric to assess their Agile implementation. Industry groups or policy-makers could also look into voluntary standard on performance framework for SMEs in the gig economy and encourage the adoption of this framework.

\subsection{Limitation and Future Research}

This is a case study. Despite providing very rich information about the Agile implementation and its respective performance, this research is not in a position to support any generalisation of this finding. Therefore, further case or meta studies in this area of research could validate or enhance the study and conclusions. Future research, either based on multiple or mixed method or meta studies could be considered in order to provide a better understanding and potential wider implications on practices and theories.

\section{Reference:}

Abrahamsson, P., Salo, O., Ronkainen, J. and Warsta, J. (2002) 'Agile software development methods: review and analysis', VTT Technical Report.

Boehm, B. (2002) 'Get ready for agile methods, with care', IEEE Computer, Vol. 35, No. 1, pp.64-69.

Boehm, B. and Turner, R. (2003) Balancing Agility and Discipline: A Guide for the Perplexed, Addison-Wesley, Boston. ISBN 978-0321186126.

Braun, V. and Clarke, V. (2006) 'Using thematic analysis in psychology', Qualitative Research in Psychology, Vol. 3, No. 2, pp.77-101.

Bryman, A. and Bell, E. (2015) Business Research Methods, 4th ed., Oxford University Press, Oxford.

Buil, I., Catalan, S. and Martinez, E. (2014) 'The importance of corporate brand identity in business management: An application to the UK banking sector', Business Research Quarterly, Vol. 19, pp.3-12.

Burmann, C., Zeplin, S. and Riley, N. (2009) 'Key determinants of internal brand management success: An exploratory empirical analysis', Journal of Brand Management, Vol. 16, No. 4, pp.264-284.

Burtch, G., Carnahan, S. and Greenwood, B.N. (2018) 'Can you gig it? An empirical examination of the gig economy and entrepreneurial activity', Management Science, Vol. 64, No. 12, pp.5497-5520.

Cockburn, A. (2000) 'Selecting a project's methodology', IEEE Software, Vol. 17, No. 4, pp.64-71.

Cockburn, A. and Highsmith, J. (2001) 'Agile software development: the people factor', Computer, Vol. 34, No. 11, pp.131-133.

Dewitt, D. (2015) Estimate Agile Projects and Improve Success. Galorath Webinar 05/08/2015. Last accessed 02/03/2017, at http://galorath.com/wpcontent/upload/2015/08/Estimate-Agile-Projects-and-ImproveSuccess080515.pdf

Dimachkie, K. (2016). Agile estimation: separating effort from risk. Last accessed 19/03/2017, at http://www.theappbusiness.com/blog/Agile-estimationseparating-effort-from-risk

Dingsoyr, T., Nerur, S., Balijepally, V. and Moe, N.B. (2012) 'A decade of agile methodologies: Towards explaining agile software development', The Journal of Systems and Software, Vol. 85, pp.1213-1221 
Dyba, T. and Dingsoyr, T. (2008) 'Empirical studies of agile software development: a systematic review', Information Software Technology, Vol. 50, No. 9, pp.833-859.

Erickson, J., Lyytinen, K. and Siau, K. (2005) 'Agile Modeling, Agile software development, and extreme programming: the state of research', Journal of Database Management, Vol. 16, No. 4, pp.88-100.

Forman, C., Ghose, A. and Wiesenfeld, B. (2008) 'Examining the relationship between reviews and sales: The role of reviewer identity disclosure in electronic markets', Information Systems Research, Vol. 19, No. 3, pp.291-313.

Fowler, M. and Highsmith, J. (2001) The agile manifesto. Last accessed 19/03/2017, at http://www.agilemanifesto.org/

Grummit, J. (1980) Interviewing Skills. London Industrial Society.

Hall, J.V. and Krueger, A.B. (2018) 'An analysis of the labor market for Uber's driverpartners in the United States', ILR Review, Vol. 71, No. 3, pp.705-732.

Hardy-Vallee, B. (2012) 'The cost of bad project management', Gallup Business Journal. Last access 01/08/2019, at http://www.gallup.com/businessjournal/152429/costbad-management.aspx\#.

Jonasson, H. (2008) Determining Project Requirements, Boca Raton, FL: Auerbach Publications.

Mahesh, K. and Suresh, J.K. (2009) 'Knowledge criteria for organization design', Journal of Knowledge Management, Vol. 13, No. 4, pp.41-51.

McConnell, S. (1997) Software Project Survival Guide, Microsoft Press.

McPherson, J. (2015) 'People Analytics from New Tech companies', New Tech Benchmark Report, Culture Amp.

Morse, A. (2015) 'Peer-to-peer crowdfunding: Information and the potential for disruption in consumer lending', National Bureau of Economic Research.

Olszewska, M., Heidenberg, J., Weijola, M., Mikkonen, K. and Porres, I. (2016) 'Quantitatively measuring a large-scale agile transformation', Journal of Systems and Software, Vol. 117, pp.258-273.

Radigan, D. (2016) 'Five Agile metrics you won't hate'. Last assessed 02/03/2017, at https://www.atlassian.com/Agile/metrics

Serrador, P. and Pinto, J.K. (2015) 'Does Agile work? - A quantitative analysis of agile project success', International Journal of Project Management, Vol. 33, No. 5, pp.1040-1051.

Shook, E. and Knickrehm, M. (2017). Harnessing revolution creating the future workforce. Accenture Strategy. Last accessed 01/08/2019, at https://www.accenture.com/usen/ acnmedia/a2f06b52b774493bbba35ea27bcdfce7.pdf

Storey, D., Steadman, T. and Davis, C. (2016) Is the gig economy a fleeting fad, or an enduring legacy? EY. Last accessed 01/08/2019, at https://gigeconomy.ey.com/Documents/Gig\%20Economy\%20Report.pdf

Sundararajan, A. (2014) Peer-to-Peer Businesses and the Sharing (Collaborative) Economy: Overview, Economic Effects and Regulatory Issues. Last accessed 01/08/2019, at https://republicans-smallbusiness.house.gov/uploadedfiles/1-152014 revised sundararajan testimony.pdf

Sveiby, K.E. (1997) The New Organisational Wealth: Managing and Measuring Knowledge-Based Assests, Berrett-Koehler, San Francisco.

Sveiby, K.E (2001) 'Knowledge-based theory of the firm'. Last accessed 01/08/2019, at: https://www.sveiby.com/article/A-Knowledge-based-Theory-of-the-Firm

Tengeler, W. (2014) 'Cone of uncertainty for Agile projects http://www.themotionstudio.nl/en/cone-of-uncertainty-for-Agile-projects/ 
Zervas, G., Proserpio, D. and Byers, J. (2015) 'The rise of the sharing economy: Estimating the impact of Airbnb on the hotel industry', Boston U. School of Management Research Paper (2013-16). 